\title{
PURCHASE BEHAVIOUR OF WOMEN CONSUMERS, TOWARDS ENERGY EFFICIENT HOUSEHOLD PRODUCTS
}

\author{
AYESHA SULTANA AHMED ${ }^{1}$, D. RATNA KUMARI ${ }^{2}$ \& T NEERAJA ${ }^{3}$ \\ ${ }^{1}$ Department of Resource Management and Consumer Sciences, College of Home Science, Professor Jayashankar Telangana \\ State Agricultural University, Hyderabad, India \\ ${ }^{2}$ Department of Resource Management and Consumer Sciences, College of Home Science, Professor Jayashankar Telangana \\ State Agricultural University, Hyderabad, India \\ ${ }^{3}$ Dean of Home Science, Acharya N. G Ranga Agricultural University, Guntur, Andhra Pradesh, India
}

ABSTRACT
Purchase of energy efficient products by consumers, for the household sector is one of the important
measures, to save on electricity consumption. Apart from cooking, heating water and lighting, a major number of
electrical appliances are being used, for drawing water for household use, room cooling, refrigeration, entertainment,
electronic products, alternative generation of power, power stabilization etc. The share of electrical appliances in
household energy consumption is likely to increase significantly in future, because of its growth in per capita incomes,
urbanization and increased end uses. Use of energy efficient products will help in reducing the burden on energy
consumption, at the household level. Hence, this study was undertaken, to understand the purchase behaviour of
women consumers towards energy efficient household products. The knowledge about star rating, energy efficiency,
energy conservation practices, adopted by consumers at household level, the reasons for the purchase of electrical
appliances was studied, through a structured questionnaire. It was found that, educational level, income and occupation
of the respondents, had an impact on the individual's purchase behaviour.
KEYWORDS: Energy Efficiency \& Star Rating.

Received: Sep 19, 2017; Accepted: Oct 09, 2017; Published: Oct 31, 2017; Paper Id.: IJECRDEC20172

\section{INTRODUCTION}

Efficient Energy Use or Energy Efficiency is the goal of efforts, directed towards reducing the power consumption in all the sectors, including domestic sector in India, especially when the generation of electricity is insufficient, it's cost of transmission high and dependence of consumers on this source is growing higher day by day. Appliances that use energy play an important role in transforming energy, into its useful forms. Based on the power being utilized, for the end use as a chief factor, electrical appliances are rated as energy efficient, as per the energy efficiency standards prescribed by the nation.

Adoption dynamics of energy efficient appliances, by purchase was studied and available in the international literature. Heterogeneous nature of consumers, net benefits received from technology per se; capital cost of technology (Jaffee et al.,2003), high energy price (Newell et al.,1999) are widely said to have influenced the adoption of energy efficient technology. As information pertaining to the Indian sub-continent is lacking on this aspect this study was taken with the major objective understanding, why these products are being purchased or not purchased by women consumers and the various factors influencing their purchase decision, and to analyze the significant difference, in the purchase behaviour of consumers who have already purchased and those who are 
considering the purchase of energy efficient household product purchase.

\section{MATERIALS AND METHODS}

This study was done with an aim, to explore the consumer behaviour of women and the guiding factors for her purchase decisions, in energy efficient products. The study was conducted in the twin cities of Hyderabad and Secundrabad. Survey research method was adopted, by using standardized questionnaire and employing a personal interview technique, to understand the purchase behaviour of women towards energy efficient household products and the factors there of influencing the purchase decisions. Only women consumers, who are in the age group of 30 -50 years were selected as population, for the study.

The size of the total sample was 200 women consumers, 100 each of those who have purchased the energy efficient household products and 100, who are considering the purchase of energy efficient household product, were the criteria for studying the purchase behaviour. The various parameters selected for studying the purchase behaviour are brand, quality, durability, function, replacement cost, lower energy consumption, star rating, appearance maintenance and price. The electrical appliances selected for the study, was based on the Bureau of Energy Efficiency scheme for energy efficiency labelling of equipments.

Under this scheme, the following equipments have been star rated.

- Frost-free(No-Frost)refrigerator***

- Tubular Fluorescent Lamps***

- Room Air Conditioners***

- Direct Cool Refrigerator

- Distribution Transformer***

- Induction Motors

- $\quad$ Pump Sets

- Ceiling Fans

- $\quad$ LPG Stoves

- Electric Geysers

- Color TV

- Laptops

*** BEE Star Label is now mandatory for these equipments from 7th January 2010.

A two-sample $\mathrm{Z}$ test was used, to analyse the significant difference in the purchase behaviour of women, who purchased and who are considering for purchase of energy efficient products, with respect to factors. Chi- square test was used to find the association, between two variables. 


\section{RESULTS AND DISCUSSIONS}

The results of the study are given below. Figures 1to 4 show the demographic profile of the respondents selected
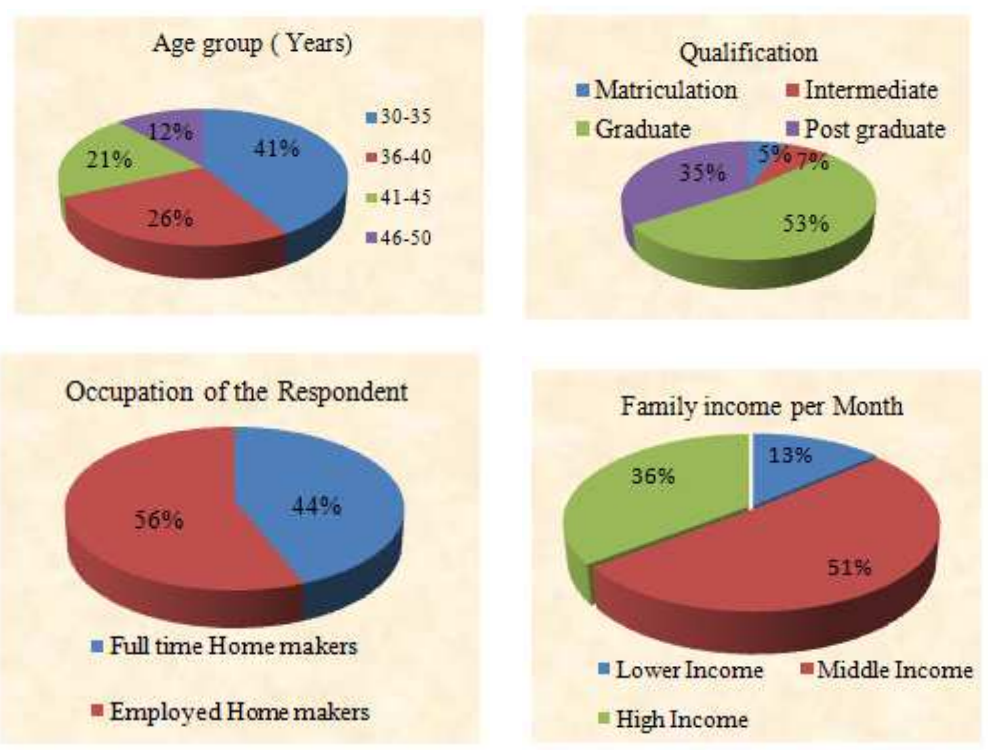

Figure 1: Profile of the Respondents

The results given in Figure 1, indicate the profile of the respondents it indicates that, only women consumers were selected in the age group of 30-50 years. The educational qualification of the respondents were divided into four categories, namely matriculation $(5 \%)$, intermediate $(7 \%)$, graduate $(55 \%)$ and post graduate $(35 \%)$. The occupation of the respondents was divided as employed home makers (44\%) and full time home makers (56\%). The income category of the respondents was divided into 3 low-income group (13\%), middle-income group (51\%) and high-income group (36\%).

\section{Pattern of use of Household Electrical Appliance}

The appliances selected for the study included tubular fluorescent lamps, ceiling fans, air conditioners, refrigerators, geysers, washing machines, televisions and desktop/ laptop.

The results revealed that

- Appliances such as ceiling fans, tubal fluorescent lights, colour television and refrigerators were used daily by cent per cent of the respondents.

- The years of usage of the appliances were limited to 5 years in the study.

- The duration of use of appliance for ceiling fans and tube lights was $<5$ hours, colour televisions, washing machine, desktop /laptop and air conditioners was used for 1-5 hours daily.

- Appliances like geysers and washing machines were used for $<30$ minutes daily.

\section{Purchase Behaviour of the Respondents}

- The purchase behaviour of the respondents was studied, based on the parameters which influenced their purchase they were brand, quality, durability, function, replacement cost, lower energy consumption, star rating, appearance maintenance and price. 
- The results suggested that, for any consumer making a purchase of an electrical equipment, the quality, brand and durability were more important than star rating, irrespective of income because household income was typically found to have positive impact, on energy-saving investments (Dillman, Rosa, and Dillman, 1983; Long, 1993; Walsh, 1989; Sardianou, 2007; Mills and Schleich, 2008).

- Environmental concerns and awareness increased with income (Fransson and Garling, 1999), leading to a greater knowledge of appliances, energy classes and adoption.

- Star rating was an important sign for energy saving and was not considered as an important factor, during the purchase. Only $50 \%$ of the high income group respondents said that, this was an important parameter while purchasing.

- In the case of middle income group 94.11 percent of said that, star rating was very important suggesting that, for this income category respondents, saving with reduced electricity bills also mattered.

- Respondents who were graduates and post graduates (i.e. with higher educational qualification), had a better knowledge about energy efficiency and star rating, when compared to those who had studied up to intermediate and matriculation.

- Graduates and post graduates considered star rating and lower energy consumption, as being more important than those who had studied upto $10^{\text {th }}$ and intermediate level.

- Education may also be positively related to the purchase of energy-saving technologies (Hirst and Goeltz, 1982; Brechling and Smith, 1994; Scott, 1997), perhaps because education, as a long term investment, is correlated with a low household discount rate.

- Attitudes towards the environment and association in social groups, disposed to environmentally friendly behaviour also tend to be positively related with education (e.g. Lutzen- hiser, 1993; Weber and Perrels, 2000).

- The above results indicated that, educational qualification, occupation and income of the respondents played a major role, in deciding the purchase of a product. These variables also worked towards analysing the respondents, understanding about the appliance.

- It has been found that, working women were more involved with the purchasing activities. They are more price and quality conscious, when compared to the non-working women.

\section{CONCLUSIONS}

The study revealed that, education increases the buyer's need for information, related to the purchase decision and thereby, to increase the value of search and the likelihood of reliance on high value, high cost sources such as consumer reports and related buying guides, as well as extensive visits to retail outlets. It was also observed that, the information on the product purchased and experienced serve as a motivating factor to the consumer's decisions, on energy efficient appliances. More so, women who are the managers of household resources and accounts; need such information so that they could rate their energy consumption, purchase decisions regarding energy efficient products and control on their buying behaviour at the market place. Awareness on the need for conservation of electricity and thereby, reducing electricity bills is an important barrier, in the adoption of energy efficient and star rated appliances that need to be 
addressed. The comparison of the two categories of the sample selected i.e., women who had already purchased and using the appliance in the last five years, and those who were in the process of considering, for purchase of energy efficient products showed that, the knowledge of the consumers has increased, over the time because now days more women were getting educated and getting acquainted with information, related to the purchase of appliances through various media. Since, they are also the managers at home they are required to be updated, with latest information. The awareness of the energy efficient appliances, also increased with the income of the respondents and it is evident that, majority of the respondents belonging to a higher income group, have a better knowledge of term 'Energy Efficiency'.

\section{REFERENCES}

1. Newell, R. G et al (1999). The induced innovation hypothesis and energy-saving technological change. Quarterly Journal of Economics 114(3): 941-75.

2. Jaffe, A. B., et al. (2003). Technological change and the environment. In K.-G. Mäler and J. R. Vincent (eds.), Handbook of Environmental Economics, Volume 1. Elsevier Science B. V.

3. Kumar, A., et al (2003). Disseminating energy-efficient technologies: A case study of compact fluorescent lamps (CFLs) in India. Energy Policy 31(3): 259-72.

4. McNeil, M., et al (2005). Potential benefits from improved energy efficiency of key electrical products: The case of India. LBNL-58254. Lawrence Berkeley National Laboratory.

5. Reddy, B. S., and Balachandra P., (2006), Dynamics of technological shifts in the household sector-Implications for Clean Development Mechanism, Energy Policy 34(16): 2586 - 99.

6. Integrated Energy Policy Report. Planning commission, Government of India (2006).

7. Dianshu F, . Sovacool BK, Vu K, (2010), the barriers to energy efficiency in China: Assessing household electricity savings and consumer behaviour in Liaoning Province, Energy Policy 38 1202-1209.

8. Mills. B and SchleichJ. 2010, what's Driving Energy Efficient Appliance Label Awareness and Purchase Propensity? Energy Policy 38 Pg, 814-825.(a)

9. Mills B and SchleichJ2013, Determinants for the Adoption of Energy-Efficient Household Appliances in Germany. Sustainable Energy Consumption in Residential Buildings, Economic Studies Volume 44, pp 39-67. (b) 
